\title{
Wireless sensor Based Landslide Detection
}

\author{
Jayant Rajaram Mali \\ M.Tech. (Electronics) \\ Rajarambapu Institute of Technology, \\ Sakharale, Maharashtra. \\ Prof. Mahesh S. Kumbhar \\ Asst. professor, \\ Rajarambapu Institute of Technology, \\ Sakharale, Maharashtra.
}

\begin{abstract}
Landslide is a common geological disaster, which seriously threats people's safety and property. This paper proposes an early warning system for a landslide. It uses an $89 \mathrm{c52}$ microcontroller to construct node. Each node contains four sensors such as moisture sensor, acceleration sensors, rain gauge, flex sensor and ZigBee are used to connect multiple nodes. Zigbee is used to transmit all reading to the receiver side through monitoring host. VB display received data or by SMS, we can alert the people and saves lives and property. The system is completely useful according to result. The efficiency of solar panel systems must be maximized to make solar energy more usable. By sun tracking, we can increase the efficiency of the solar panel.
\end{abstract}

Keywords - Landslide, Sensors, Zigbee, Microcontroller, Sun-Tracking

\section{INTRODUCTION}

In India, hilly areas like Himalayan Mountains, Western Ghats and north eastern part landslide have been a major issue which causes life loss and property loss. India faces landslides every year with a large threat to human life causing the annual loss of US 400 million dollars. For example, On 30 July 2014, a landslide occurred in the village of Malin in the Ambegaon Taluka of the Pune District in Maharashtra, India. The landslide, which hit early in the morning, which was believed to have been caused by a heavy rainfall and killed at least 134 people.

Landslide contains all type of mass movement of hill slopes and it is defined as the movement of material on a slope. The material is a mixture of rocks, soils, artificial fills etc. They may move by falling, sliding, spreading. Some landslide occurs quickly, whereas other may take hours, week, month or even longer develop. Many factors responsible for landslide such as Gravity, Geology, Groundwater, Wave action, Human action

In order to avoid the impact of the landslide, landslide monitoring is very important. Landslides are geological term causing loss of life and loss of properties. Therefore, technology has to be developed to give signals with minimum monitoring delay. Wireless sensors are used because it can quickly respond to rapid changes of data and send data to receiver section. It consists of ZigBee network, GPRS/ GSM module, solar panel. Zigbee uses as hardware functions to construct ZigBee wireless sensor network and then uses GSM/GPRS for data transmission and earlier warning information.

It has versatility and good scalability, it can overcome the traditional monitoring method of single function which function is low and cost is high; it can effectively achieve landslide monitoring and prevention of the adverse geological condition under the mountains. 


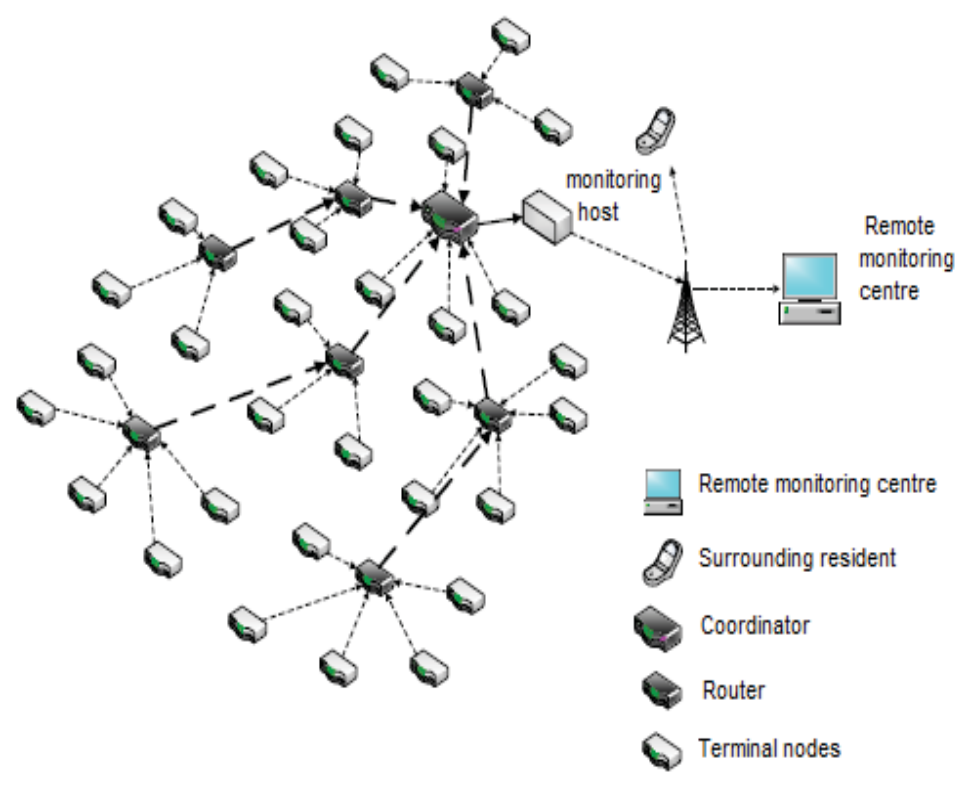

Fig. 1 Overall Architecture

\section{WIRELESS SENSOR NODE}

Wireless nodes consist of moisture sensor, flex sensor, accelerometer, rain sensor, solar panel, power supply module.

The moisture sensor is KG-003, used to measure water content in the soil. Measuring the capacitance between two electrodes placed in the soil, the soil water content is determined. It has fixed bolt hole, convenient installation. In this we using two probes to be placed in the soil we will get analogue output changes from 0.60volts-5volts.

The accelerometer is ADXL335. It is small, Thin, low power, 3 axis accelerometer with high-resolution measurement at up to $16 \mathrm{~g}$. The sensor is fabricated from poly silicon and To implement open-loop acceleration measurement architecture, it uses signal conditioning circuitry. This sensor comes with 3 analogue output for X, Y and $\mathrm{Z}$ axis breakout board. The $\mathrm{VCC}$ take up to $5 \mathrm{~V}$ in and regulates it to $3.3 \mathrm{~V}$ with an output pin.

To measure soil movement like very slow creep movements or sudden movement Flex $22^{\prime}$ flex sensor is used. It is operated in Temperature Range of $-35^{\circ} \mathrm{C}$ to $+80^{\circ} \mathrm{C}$. It tolerates up to $30 \%$ tolerance

The rain sensor is used to measure the intensity of the rain. The effect of rain infiltration on a slope such as increases depth of main water table or weight of soil rising, also changing soil suction and positive pore pressure and reducing the anti-shear which causes a landslide. 


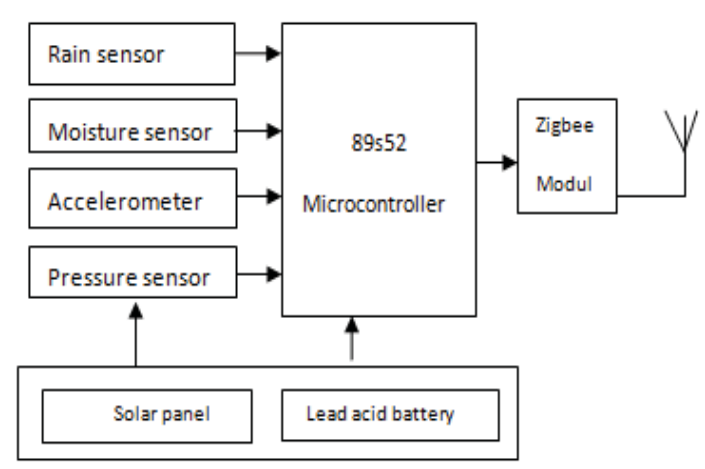

Fig. 2. Transmitter Section

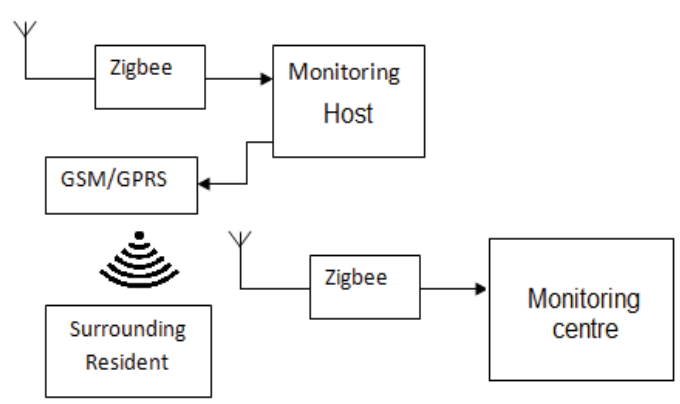

Fig3. Receiving section

\section{POWER MANAGEMENT MODULE}

An important part of the system is power management module, directly related to the system performance. The stable power supply is required for terminal node.

Solar energy is one of the clean and natural energy, that not only reduce environmental pollution but also provide alternative energy resources. The efficiency of solar panel can be improved using sun tracking.

At the platform, power supply depends on the lead acid battery and solar panel, the solar panel is used to charge the battery at day time. Platform work continuously without replacing the battery.

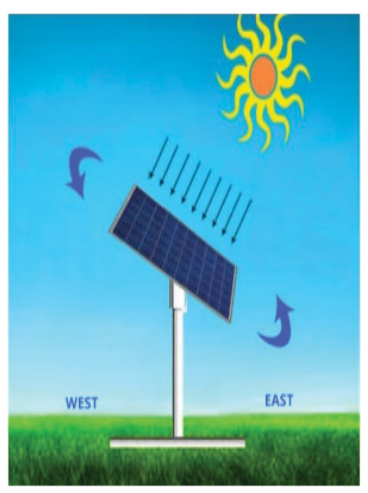

\begin{tabular}{|c|c|c|}
\hline INPUTA & INPUT B & OUTPUTC \\
\hline 0 & 0 & 0 \\
\hline 0 & 1 & Anti-Clock Wise \\
\hline 1 & 0 & Clock Wise \\
\hline 1 & 1 & 0 \\
\hline \multicolumn{2}{|c|}{ Table: Various Modes of Motor Rotation } \\
\hline
\end{tabular}

Fig.4. Solar Tracking 


\section{MONITORING HOST}

At monitoring host, ATmega328 controller is used because it requires low power, stable processing speed. Zigbee and also GPRS module available in monitoring host. It is communication interface between sensor nodes and monitoring centre. During normal operation monitoring host send data to monitoring centre, if any sensor detect value above threshold value then GPRS send data to surrounding resident.

\section{ZIGBEE}

For communication purpose, zigbee module is used. We have four ZigBee modules two at the transmitter, one at monitoring host and another at the receiver side. For communication purpose, we don't need any external signal, so we use ZigBee module. In this peer to peer, communication is performed. the transmitter side data transmitted by transmitter ZigBee, which is obtained from the controller it transmits without having a delay. Then receiver side ZigBee receives the signal and automatically receives data transmitted from the transmitter. In this, we don't have data loss so it is safe.

\section{GPRS DESIGN}

In slip power mode GPRS chip has consumed 2.5ma current with large frequency band and built-in TCP/IP protocol has available, and its operating voltage is $3.4 \mathrm{v}-4.5 \mathrm{v}$.for high-speed transmission of data like voice, SMS, and FAX information, I programme module by AT command. Using this command I can achieve bidirectional data transmission and it also supports multiple SMS format. For network communication, the module sends AT commands and SMS through a serial port, the whose biggest advantage is that the instructions related to the response and information exchange with the network are done automatically inside the module. When the module is powered on, the network logged on automatically and kept. So the module is high real-time, without dial-up time. 


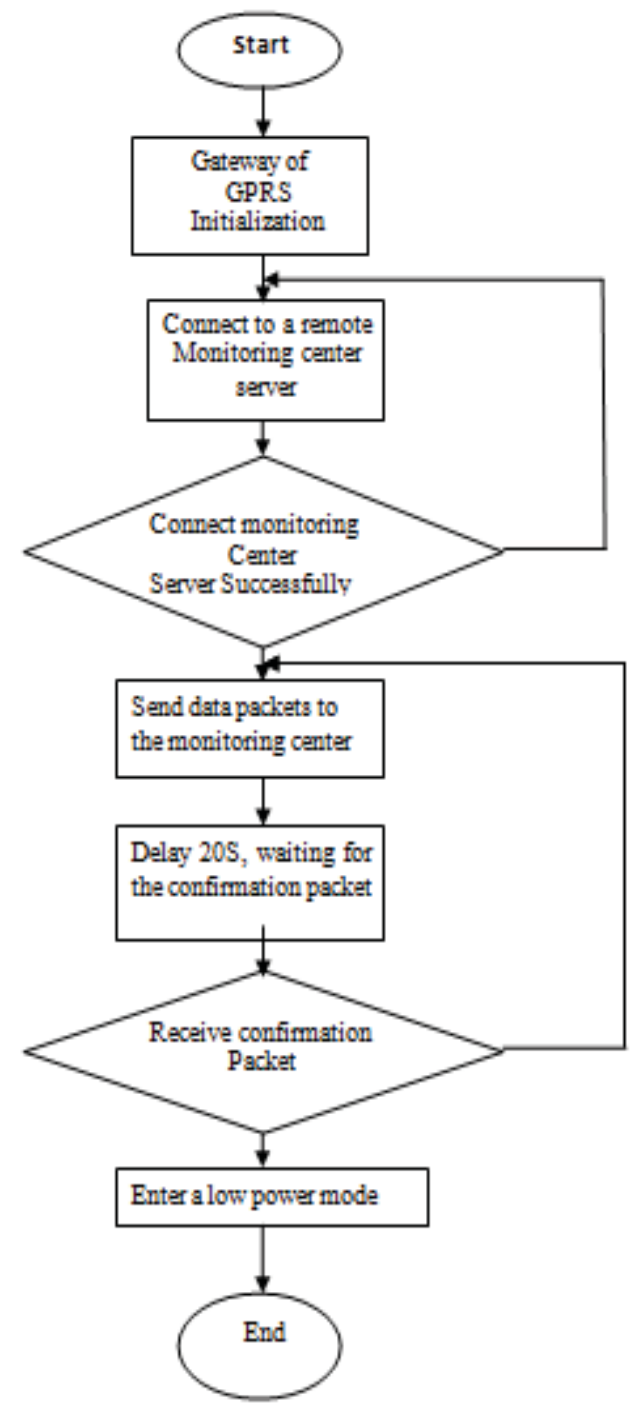

Fig.5. GPRS Network Connection Process

\section{VISUAL BASIC}

Visual basis is a guide user interface. Visual basic is used to display all information collected from sensor node through GSM/GPRS. It displays continuously reading from two sensor nodes. In this two windows are used to display all sensor information from two nodes. Each window contain four text block to display readings countineously. 


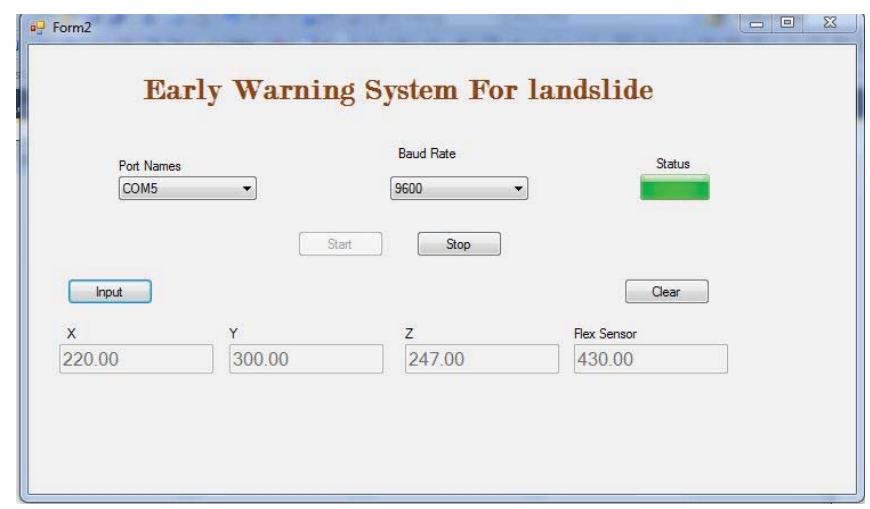

Fig.6. Result from acceleration sensor and flex sensor on VB

\section{RESULTS}

Various experiments have been performed in order to check the performance of this system and especially the ability of the system to provide data in a real-time manner.

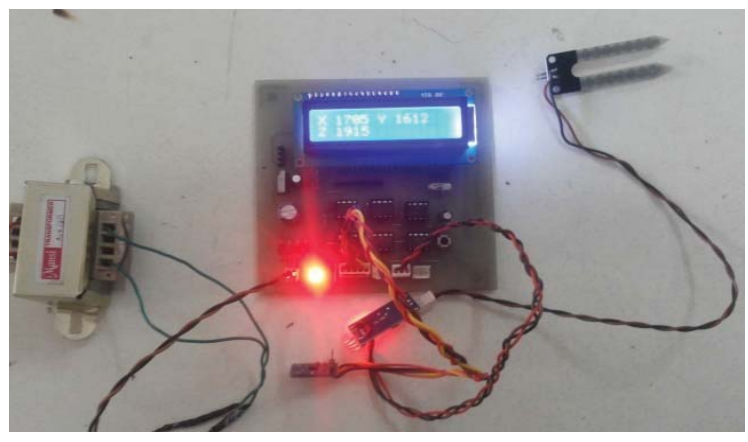

Fig.7 Hardware circuit of sensor node

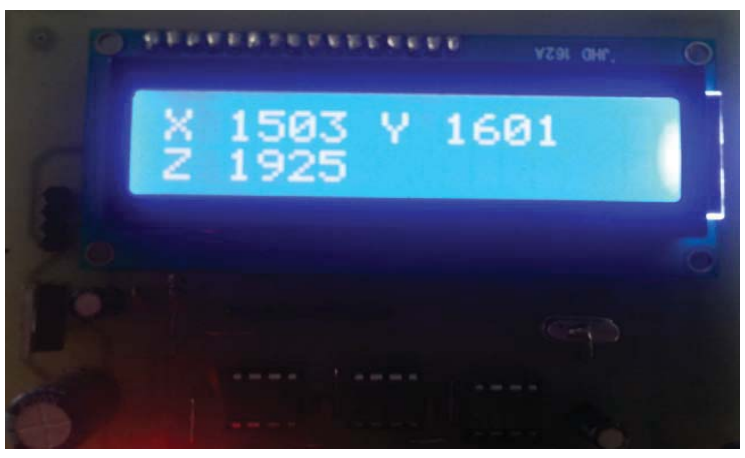

Fig.8 Reading from accelerometer 


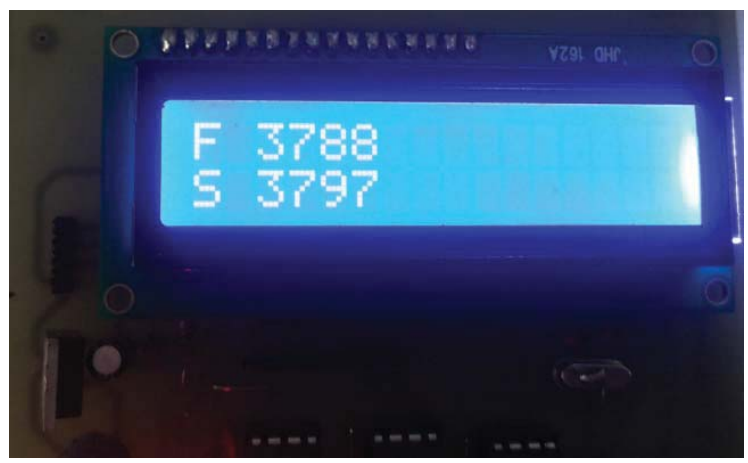

Fig.9 Reading from flex sensor and moisture sensor

\section{CONCLUSION}

We have designed the real-time system for landslide detection. This system is developed using the $89 \mathrm{~s} 52$ controller and ATmega328 controller. The main component used in this system are ZigBee, GPRS/GSM. We have attached three sensors like moisture sensor, accelerometer, rain sensor, flex sensor. In this transmitter section, we have sensors connected to $89 \mathrm{c} 52$ controller. Data collected from sensors send to monitoring centre through monitoring host. If monitoring host detects any value above threshold value then it sends to surrounding resident

\section{REFERENCES}

[1] Jian Xu, yuan hong wang, yu zhang and Shushan yang "intelligent early-warning system for landslide base on ZigBee network" 978-14799-3381-5/13 DOI 10.1109/DASC.2013.60

[2] Jiexian Zeng, Yonglong Yu, Bo Tian "landslide monitoring based on computer vision technology"978 14799-3197-2/IEEE 2014

[3] Ming-Chih Lu, Tien-Yu Tang, Cheng Pei Tsai And Yu-An "The Non-Contact Landslide monitoring system for long-distance" 978 1-42445143 2/10/IEEE 2010

[4] Fabio Bowen GA, Elena Miami, Raffaele Nutricato, maria Teresa Chiara DIA"GIS-based system for landslide early warning index measurement" IEEE international conference on virtual environment, human computer interface and measurement system Ostuni-Italy 2527 june2007

[5] Maneesha vino Dini Ramesh "integrating geophone network to real-time wireless sensor network system for landslide detection “ 2010 IEEEDOI 0.1109/SENSORDEVICES.2010.39

[6] Ming-the wu, mon-shieh yang, Huang-Chen Liu, and jin-king liu "landslides volumetric estimation by using lidar data and and sediment production rate method" landslides, vol. 1, no. 3, pp. 203-209,2011

[7] M.Chigira, F.Duan, H.Yagi Et Al., "Using An Airborn Laser Scanner For The Identification Of Shallow Landslides And Susceptibility Assessment In An Area Of Ignimbrite Overlain By Permeable Pyroclastics,Landslides, Vol. 1,No. 3, Pp.203-209, 2008

[8] Pick J, Mukherjee B, Ghosal D. Wireless Sensor Network Survey[J].Computer Networks, 2008, 52(12): 2292- 2++330

[9] Garcia-Hernandez C F, Ibarguengoytia-Gonzalez P H, Garcia-Hernandez J, Et Al. Wireless Sensor Network And Application Journal Of Computer Science And Network Security, 2007, 7(3):264-273.

[10] Lynch $\mathrm{j} \mathrm{p}$, loh $\mathrm{k} \mathrm{j}$. a summary review of wireless sensors and sensors network for structural health monitoring[j]. shock and vibration digest, 20 38(2): 91-130 